Revue

Revue de l'histoire des religions

del'histoire

des religions

$3 \mid 2008$

Varia

\title{
Jean-Pierre Moisset, Histoire du catholicisme
}

\section{François Laplanche}

\section{OpenEdition \\ Journals}

Édition électronique

URL : http://journals.openedition.org/rhr/6823

DOI : 10.4000/rhr.6823

ISSN : 2105-2573

Éditeur

Armand Colin

Édition imprimée

Date de publication : 1 septembre 2008

Pagination : 437-439

ISBN : 978-2200-92445-4

ISSN : 0035-1423

\section{Référence électronique}

François Laplanche, « Jean-Pierre Moisset, Histoire du catholicisme ", Revue de l'histoire des religions [En ligne], 3 | 2008, mis en ligne le 14 janvier 2010, consulté le 22 septembre 2020. URL : http:// journals.openedition.org/rhr/6823 ; DOI : https://doi.org/10.4000/rhr.6823

Tous droits réservés 
guerre. Le christianisme entre alors au service d'une critique des doctrines de la guerre juste, dénoncées comme illégitimes et immorales, comme autant de discours justifiant la raison d'État.

Le collectif se poursuit par une série d'articles qui explorent d'autres champs que ceux du christianisme européen moderne et contemporain. Une première ouverture vers le monde romain (Baudouin Decharneux), qui analyse le droit fécial et la pratique de la devotio décrites dans deux récits de batailles (Veseris et Sentinum), met en lumière la cohérence religieuse du monde romain, dans le sillage des analyses de Georges Dumézil, et la dimension du code symbolique qui investit les pratiques guerrières. Une autre ouverture a lieu vers l'islam médiéval, qui a codifié la guerre d'autant plus tôt que la lutte fut un élément de mission du Prophète. Comme le montre Jean-Charles Ducène, si la doctrine classique de la guerre sainte est élaborée au $\mathrm{IX}^{\mathrm{e}}$ siècle et réactualisée aux $\mathrm{XII}^{\mathrm{e}}$ et $\mathrm{XIII}^{\mathrm{e}}$ siècles, elle devient au XIX $\mathrm{X}^{\mathrm{e}}$ siècle - du fait de l'occidentalisation des mentalités et du droit - un discours politique, en même temps qu'elle ne se conçoit plus qu'envers les infidèles. Très présente également dans le texte biblique hébraïque, la question de la guerre traverse l'histoire juive, au point de constituer, pour Régine Azria, une sorte de fil rouge reliant l'Antiquité au présent, les textes fondateurs, leurs commentaires théologiques et philosophiques, au sionisme et à l'histoire nationale israélite. Si les textes fondateurs comprennent tout à la fois une typologie des guerres et un usage éthique de la violence, les trois périodes définissant un rapport spécifique à la guerre (biblique, exilique et post-exilique) apportent des références sur lesquelles se fondent des positions aussi différentes que le bellicisme hérö̈que, le mysticisme messianique ou apocalyptique. Jean Lévi oriente pour finir cette étude des théologies de la guerre vers l'Extrême-Orient, développant une analyse du Sunzi - texte paradigmatique de la pensée chinoise de l'art de la guerre écrit vers la fin du IV siècle avant notre ère, à une période de transformation en profondeur de la Chine.

Ce collectif offre ainsi une approche véritablement plurielle des théologies de la guerre, tant par ses ouvertures géo-temporelles justifiées par une approche historique comparatiste, que par les champs disciplinaires qu'il mobilise, liant la théologie au droit, à l'histoire et à la théorie politique.

Julie SAADA, IUFM de Paris, Université Paris 9.

Jean-Pierre Moisset, Histoire du catholicisme, Paris, Flammarion, 2006, $24 \mathrm{~cm}, 529$ p., $24 €$.

Dans la collection de synthèse historique où paraît cet ouvrage, il se distingue par l'étendue exceptionnelle du sujet traité. Et l'on peut considérer que l'auteur a gagné son pari en fournissant en cinq cents pages une vision 
claire et informée de l'histoire du catholicisme. Malgré cette densité, l'écriture du livre est agréable et il se lit facilement. Il pourrait éventuellement servir de guide à qui veut s'initier à ces vingt siècles d'histoire, même si certains passages méritent discussion. Tout ce qui concerne l'histoire interne du catholicisme est généralement très bien venu : formes de la piété, fondations ou réformes des ordres religieux, rôle entraînant des saints. L'auteur dessine aussi d'un trait ferme le rôle historique de la papauté, défenseur obstiné, en ses meilleurs moments, de l'indépendance du spirituel. Il ne cache pas certaines erreurs ou fautes de l'Église catholique : l'Inquisition, la traite des noirs, les silences de Pie XII non seulement sur la «solution finale » choisie par les nazis pour le peuple juif, mais même sur la persécution du clergé polonais durant la seconde guerre mondiale. Enfin l'ouvrage ouvre d'intéressantes perspectives sur les rapports entre le catholicisme et les sociétés contemporaines. On peut donc considérer que, tout en gardant son style personnel et ses options, cette Histoire du catholicisme recueille les meilleurs résultats de l'historiographie religieuse contemporaine, tels qu'ils s'exposent plus longuement, par exemple, dans les quatorze volumes de l'Histoire du christianisme, publiés chez Desclée de 1990 à 2000.

Pour autant l'auteur n'a pas oublié les leçons de l'histoire ecclésiastique traditionnelle, qui privilégiait les règnes des papes, leurs démêlés avec les princes, l'importance des conciles et, dans cette perspective, il souligne l'apport, à ne pas négliger, de l'Histoire de l'Église de Fliche et Martin (en 24 vol., parus de 1934 à 1964, chez Bloud et Gay). De cette vision du catholicisme par lui-même, l'auteur retient qu'elle a bien perçu la place centrale de la papauté dans une évolution séculaire où elle se dessine de plus en plus. Selon la représentation que le catholicisme se fait de ses origines, ce rôle de l'évêque de Rome est dit être en continuité avec celui qu'il tenait dans l'Église des apôtres. Mais J.P.M., sans ignorer les critiques adressées à cette position, prend, ici et ailleurs, le parti de décrire le catholicisme tel qu'il se comprend, sans agressivité et sans complaisance. Ceci pourrait expliquer qu'il s'attache au conflit entre les Lumières françaises et l'Église catholique, en laissant explicitement en marge le rapport entre le christianisme en général et la culture européenne. Le conflit philosophique ayant tourné à l'affrontement violent, même sanglant, qui enténèbre l'histoire religieuse de la Révolution française, le catholicisme du XIX ${ }^{\mathrm{e}}$ siècle vit de ces souvenirs et ne perçoit pas en profondeur les transformations de la culture qui sont en train de s'effectuer. Au final, le procès catholique des Lumières, selon le récit de J.P.M., emprunte à la représentation que se sont forgée d'elles la majorité des évêques et des théologiens de cette époque, avant comme après la Révolution française (par exemple l'essentielle nocivité des philosophies de Descartes et de Kant). Procès sanctionné par le Proemium de la constitution Dei Filius du concile Vatican I, dû à la plume de Pie IX et largement diffusé par la presse intransigeante. Le résultat de ce refus et de cette condamnation a été d'obstruer le chemin (familier 
pourtant au catholicisme) de l'adaptation aux cultures environnantes. Tout se passe à partir du XVIII ${ }^{\mathrm{e}}$ siècle comme si le catholicisme s'était de lui-même arraché à son "génie ». En tout cas, l'affirmation est claire à la fin de la préface, sans doute plus que dans le chapitre intitulé « le choc des Lumières ».

Il faut d'ailleurs aller plus loin: non seulement le christianisme ne forme plus le moule culturel de l'Occident, mais ses croyances et son histoire sont devenues un simple objet pour les sciences sociales. L'affrontement symbolisé en France par les noms de Renan et de Loisy a commencé à l'abri de la science historique, et, sur ce point, le lecteur français aurait aimé en savoir un peu plus long. Nous touchons là un point névralgique de l'historiographie du catholicisme en France : le cloisonnement des disciplines autant que l'amaigrissement de la corporation des prêtres-historiens rend plus difficile l'élaboration d'une histoire culturelle ou « intellectuelle » de l'objet « religion » et certains «blancs » de la collection Histoire du christianisme en témoignent ouvertement. À cette situation sont apportés des remèdes sous formes d'écoles ou d'universités d'été. Mais la brièveté des sessions et la variété des sujets inviteraient à des initiatives plus amples.

François LAPLANCHE, Centre national de la Recherche scientifique. 